\title{
Mark C. Hersam Named 2010 MRS Outstanding Young Investigator for Nanoelectronic Materials
}

Mark C. Hersam, Professor of Materials Science and Engineering and Professor of Chemistry at Northwestern University, has been named the 2010 Materials Research Society Outstanding Young Investigator. Hersam was cited for "pioneering research on the physics, chemistry, and engineering of nanoelectronic materials and devices, including solution phase techniques for sorting carbon nanotubes and graphene, and for organic functionalization and nanopatterning of semiconductor surfaces." He will deliver an award talk at the Materials Research Society Spring Meeting in San Francisco.

At Northwestern, Hersam's projects range from molecular electronics to surface science, energy research, and biotechnology. A key example is his work on using density gradient ultracentrifugation (DGU) to sort carbon nanotubes with chiral-level control. Synthetic techniques for carbon nanotubes produce mixtures with a range of physical structures and properties, yet this very inhomogeneity has prevented their use in many applications. Hersam has now translated his approach into a commercially viable technology, forming a start-up company, NanoIntegris, which produces and distributes separated nanotubes. He has recently extended his purification method to double-walled carbon nanotubes [Nature Nanotechnology 4, 64 (2009)] and graphene [Nano Letters 9, 4031 (2009)]. For graphene, Hersam's method sorts by the number of layers, which is cru-

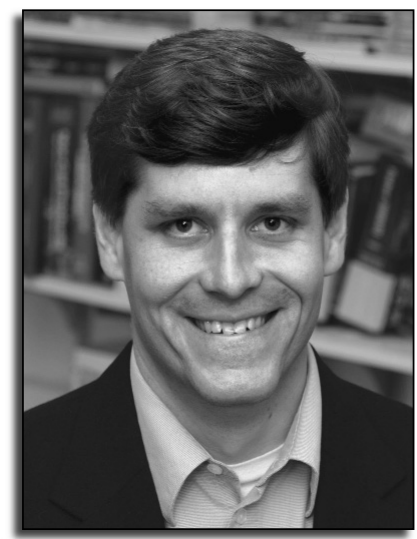

Mark C. Hersam

cial for emerging graphene nanoelectronic devices.

In earlier work, Hersam used ultrahigh vacuum (UHV) scanning tunneling microscopy (STM) to elucidate the structures and electronic properties of individual molecules on silicon surfaces. Achievements include characterization of surfacemounted molecular rotors and single molecule charge transport measurements on silicon-based molecular electronic devices. His work has induced a paradigm shift in the field of molecular electronics from the study of molecules that use metal-molecule junctions to those that employ semiconductor-molecule junctions. Hersam has also developed a nanofabrication technique-called feedback-controlled nano- lithography - that enables direct covalent attachment of organic molecules to silicon surfaces with atomic-scale spatial resolution. He is now extending his UHV STM efforts to organic functionalization and nanopatterning of epitaxial graphene surfaces [Nature Chemistry 1, 206 (2009)].

Hersam received his $\mathrm{BS}$ and $\mathrm{PhD}$ degrees in electrical engineering from the University of Illinois at UrbanaChampaign in 1996 and 2000, respectively. He received his MPhil degree in physics from the University of Cambridge, U.K., in 1997. After serving as a research aide at Argonne National Laboratory (1996) and as a research intern at IBM T.J. Watson Research Center (1999), he joined the faculty at Northwestern University in 2000 where he quickly advanced to full professor in the Materials Science and Engineering Department (MSE) in 2006 and in Chemistry in 2007. He is a three-time recipient of the Teacher of the Year award in the MSE department (2003, 2007, and 2009). Among Hersam's other honors are the British Marshall Scholarship (1996) and, more recently, the Presidential Early Career Award for Scientists and Engineers, the ONR Young Investigator Award, the ARO Young Investigator Award, and the Alfred P. Sloan Research Fellowship, all in 2005. In 2006, he received the AVS Peter Mark Award and the TMS Robert Lansing Hardy Award. Hersam has two patents issued, 14 patents pending, and over 100 publications.

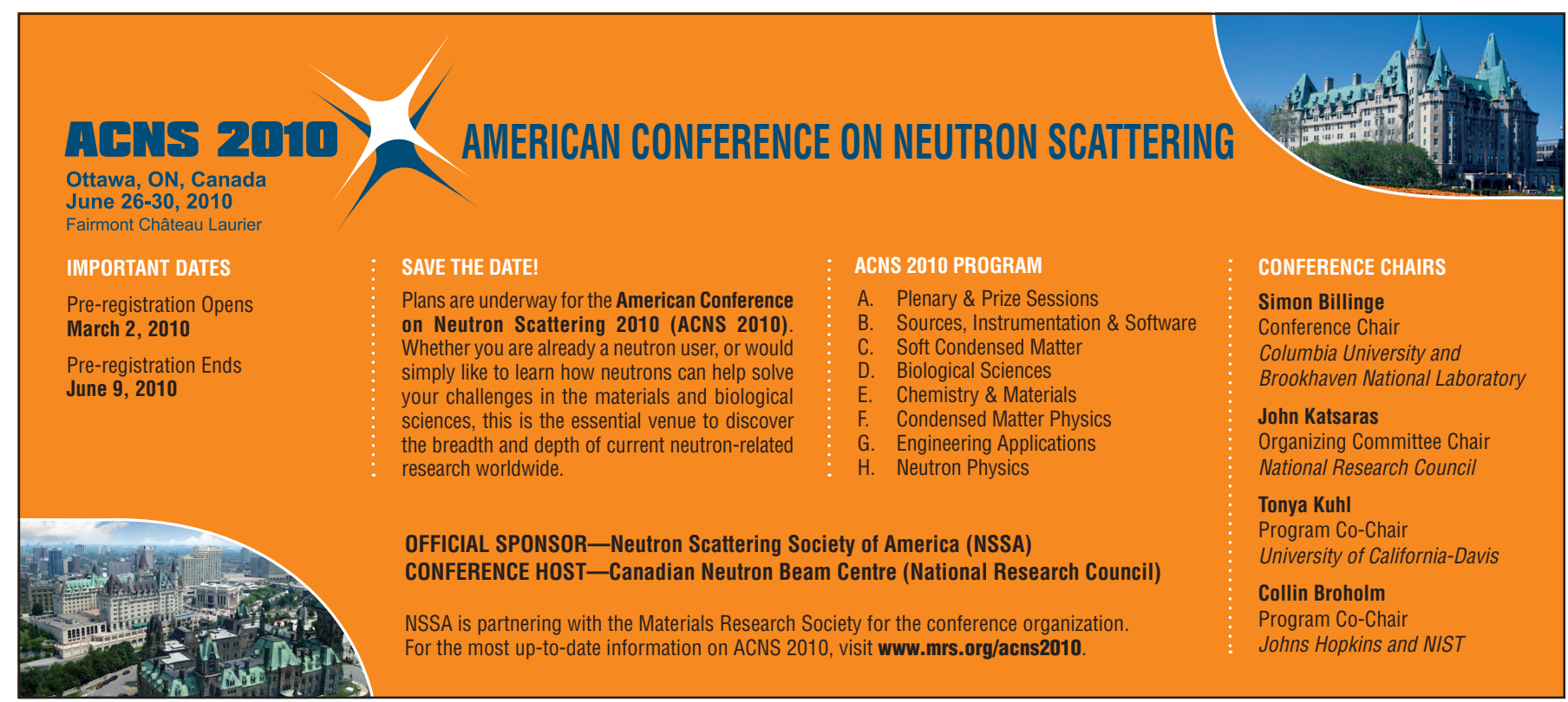




\section{Oliver and Pharr Receive Inaugural MRS Innovation in Materials Characterization Award}

Warren C. Oliver of Nanomechanics, Inc. in Oak Ridge, Tenn., and George M. Pharr of the University of Tennessee and Oak Ridge National Laboratory have been honored with the inaugural MRS Innovation in Materials Characterization Award for their joint work on nanoindentation. Oliver and Pharr were cited for "seminal contributions to the development of the instrumentation and analysis methods of nanoindentation for characterizing the mechanical properties of materials at the micro- and nanometer length scales. Their work on nanoindentation has profoundly impacted all fields of materials research where mechanical behavior is important." Oliver and Pharr will be presented with the award at the 2010 Materials Research Society Spring Meeting in San Francisco.

Oliver's co-invention (with John Pethica) of the first commercially successful depth-sensing nanoindenter and Oliver and Pharr's subsequent development of robust methods for determining basic mechanical properties from depthsensing indentation experiments, essentially founded nanoindentation as a powerful method for characterizing the mechanical properties of materials at the length scales appropriate to modern devices and structures. The methods they developed have been universally adopted and have contributed significantly to the reliable manufacture of advanced materials and devices.

The centerpiece of Oliver and Pharr's work is their article on the determination of the hardness and elastic modulus using depth-sensing indentation [Journal of Materials Research 7 (6) (1992) 1564]. The methods they developed for determining the shape of the indenter tip using contact stiffness measurements, using calibration materials with known elastic properties, and the contact depth from load, displacement, and stiffness alone, using an insightful result from contact mechanics, are now widely accepted and used throughout the world. Most recently, Oliver and Pharr have developed new, robust methods for determining the anelastic and damping properties of materials by nanoindentation [Journal of Applied Physics D 41 (7)(2008) 074021; JMR 24 (3)(2009) 626; both articles are coauthored with E.G. Herbert and A. Lumsdaine]. This is a non-trivial problem

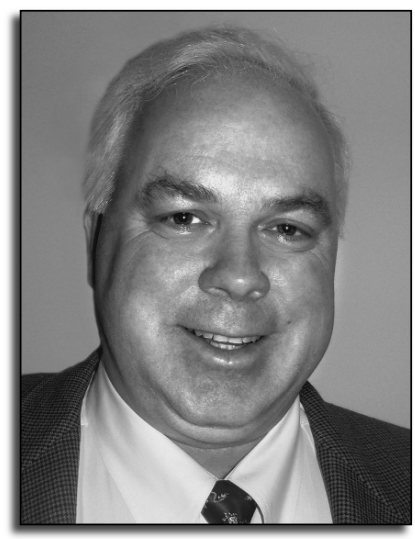

Warren C. Oliver

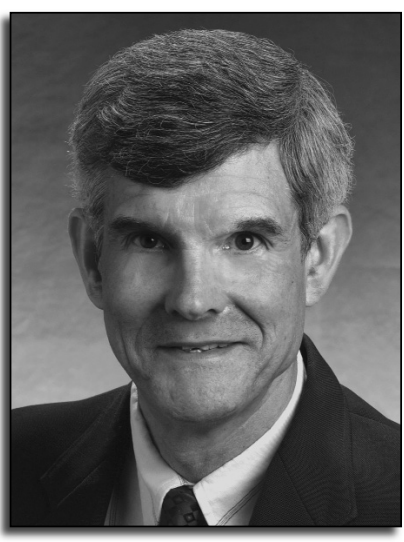

George M. Pharr because the fundamental damping processes in the contact are combined with the damping characteristics of the instrument, requiring sophisticated testing and analysis methods to separate the two.

Oliver is currently president of Nanomechanics, Inc. He received his $\mathrm{PhD}$ degree from Stanford University in 1981. From 1983 to 1998, he was co-founder and president of Nano Instruments, Inc. in Oak Ridge. During that time, he also served as a research scientist at Oak Ridge National Laboratory (ORNL) and an adjunct professor of materials science at Vanderbilt University. From 1998 to 2001, he was vice president, Nano Instruments Innovation Center/MTS Corporation, where he later became general manager (2004-2008). Nano Instruments was acquired by Agilent Technologies in 2008, where he served as senior scientist prior to forming a new venture at Nanomechanics, Inc. Since 1999, Oliver has served as cofounder and board member of Fast Forward Devices LLC in Oak Ridge and as adjunct professor of materials science at the University of Tennessee (UT). Oliver's honors include the MTS Corporation Circle of Innovators Award, a Department of Energy Award for Significant Implication for DOE Related Technologies in Metallurgy and Ceramics, and the Ross Coffin Purdy Award, and Oliver holds numerous patents.

Pharr is Chancellor's Professor, McKamey Professor of Engineering, and head of the Department of Materials Science and Engineering at the University of Tennessee, and a joint faculty member in the Materials Science and Technology Division at the Oak Ridge National Laboratory. He received his PhD degree from Stanford University in 1979. He was on the faculty at Rice University from 1980 to 1998 and during that time, Pharr also served as Visiting Scientist at both IBM and ORNL and as Master of Wiess College at Rice University. He joined UT in 1998. In 2002-2005, he served as Adjunct Professor of Biomedical Engineering at the University of Memphis, and since 2009 he has been director of the UT/ORNL Joint Institute for Advanced Materials. Pharr is currently on sabbatical leave as a Visiting Scientist at the Karlsruhe Institute of Technology in Germany. Pharr's most recent award is the Humboldt Research Award for Senior U.S. Scientists. Among his professional activities, Pharr chaired the 1995 Materials Research Society Spring Meeting and the 2000 Gordon Research Conference on Thin Film Mechanical Behavior; he served as a volume organizer in 2000 for MRS Bulletin and as guest editor for $J M R^{\prime} s$ special focus issues on nanoindentation (2004 and 2009). Pharr has numerous publications.

The Innovation in Materials Characterization Award honors an outstanding advance in materials characterization that notably increases the knowledge of the structure, composition, in situ behavior under outside stimulus, electronic, mechanical, or chemical behavior, or other characterization feature, of materials. The award has been endowed by Toh-Ming Lu and Gwo-Ching Wang. MIRS 